\title{
"No olvidemos a los muertos". Animero y violencia en Puerto Berrío, Antioquia (Colombia)*
}

DOI: https://doi.org/10.18046/recs.i28.3328

\author{
"Let's not forget the dead". Animero and Violence \\ in Puerto Berrío, Antioquia (Colombia) \\ "Nao vamos esquecer os mortos". Animero e violência \\ em Puerto Berrío, Antioquia (Colômbia)
}

\author{
Helwar Hernando Figueroa-Salamanca ${ }^{* *}$ \\ Universidad Industrial de Santander (Bucaramanga, Colombia)
}

\section{Claudia Lorena Gómez-Sepúlveda ${ }^{* * *}$}

Universidad Pontificia Bolivariana (Bucaramanga, Colombia)

\footnotetext{
* Artículo de investigación elaborado en el marco del Taller Sobre el Estudio del Conflicto y los Movimientos Sociales en Colombia, adscrito al grupo de investigación Sagrado y Profano, avalado por la Universidad Industrial de Santander y presentado en una primera versión en IV Jornadas de Religión y Sociedad en la Argentina Contemporánea y países del Cono Sur, Buenos Aires, 24-26 de junio de 2015. Su investigación duró dos años y se realizó con financiación propia. Artículo de investigación recibido el 17.12.2018 y aceptado el 24.05.2019.

** Profesor titular de la Universidad Industrial de Santander, UIS. Historiador de la Universidad Nacional de Colombia, Magíster en Historia y Doctor en Estudios Latinoamericanos de la Universidad de Toulouse, Francia. Miembro del grupo de investigación Sagrado y Profano. Correo electrónico: helwarff@uis.edu.co ORCID: https://orcid.org/ooooooo2-4310-9124

*** Joven Investigadora de Colciencias adscrita a la Universidad Pontificia Bolivariana. Historiadora y Archivista de la Universidad Industrial de Santander, UIS. Miembro del grupo de investigación Sagrado y Profano. Correo electrónico: c.lorenagomez@hotmail.com ORCID: https://orcid.org/oooo-ooo2-9244-0497
} 


\section{Cómo citar/How to cite}

Figueroa-Salamanca, Helwar Hernando; Gómez-Sepúlveda, Claudia Lorena (2019).

"No olvidemos a los muertos". Animero y violencia en Puerto Berrío, Antioquia (Colombia).

Revista CS, 28, 125-151. https://doi.org/10.18046/recs.i28.3328 
Resumen

Abstract

Resumo

Este artículo describe una práctica de religiosidad popular: la adoración a las ánimas del purgatorio y a los muertos tirados al río Magdalena, en Puerto Berrío, Antioquia. Se trata de una creencia mantenida vigente por medio de la figura del animero, quien representa la identidad, devoción y memoria comunitaria del puerto, potenciada por los cadáveres que encallan en sus orillas y que son adoptados religiosamente por sus habitantes. En estos ritos, les dan nombres, los entierran dignamente y rezan por ellos en contra del olvido deseado por sus victimarios. Adoptar los NN en esta zona gravemente afectada por el conflicto armado, contribuye a recrear la memoria de los muertos y, de esta manera, fortalecer su identidad en relación con la figura del animero. Esta descripción se logró con la observación participante, con entrevistas a los porteños y con la historia de vida del actual animero.

PALABRAS CLAVE:

religiosidad popular, violencia, Puerto Berrío, animero

This article describes a popular religious practice: the worship of the Souls of Purgatory and the dead bodies thrown into the Magdalena River in Puerto Berrio, Antioquia. This practice is a current belief maintained through the figure of the animero, who represents the identity, devotion, and community memory of the port, enhanced by the corpses that run aground along the river banks and that are religiously adopted by its inhabitants. In these rituals, the locals give names to the corpses, they bury them with dignity and pray for them against the oblivion desired by their perpetrators. Adopting the victims with unknown identity or John Does in this area, severely affected by the armed conflict, helps to recreate the memory of the dead and thus strengthens the identity of the corpses in relation to the figure of the animero. This description was achieved through participant observation, interviews with the locals, and the life story of the current animero.

\section{KEYWORDS:}

Popular Religiosity, Violence, Puerto Berrío, Animero 
Este artigo descreve uma prática da religiosidade popular: a adoração das Almas do purgatório e os mortos jogados no rio Magdalena em Puerto Berrío, departamento de Antioquia, na Colômbia. É uma crença mantida em vigor através do animero (em português, pessoa que no mês de novembro convida as almas na dor a caminhar pelas ruas de um povoado implorando uma oração que facilitasse seu descanso eterno), que representa a identidade, devoção e memoria comunitária do porto, reforçada pelos cadáveres que encalham nas suas margens e que são adotados religiosamente pelos seus habitantes. Nesses ritos eles dão nomes, os enterram com dignidade e oram por eles contra o esquecimento desejado por seus vitimizadores. Adoptar o N.N. (pessoa sem identificar) nesta área, seriamente afetada pelo conflito armado, ajuda a recriar a memória dos mortos e assim fortalecer sua identidade em relação à figura do animero. Esta descrição foi conseguida com a observação participante, com entrevistas aos portenhos e com a história de vida do animero atual.

\section{PALAVRAS-CHAVE:}

religiosidade popular, violência, Puerto Berrío, animero 


\section{Introducción}

En el municipio de Puerto Berrío, Antioquia, la devoción a las ánimas del purgatorio se mantiene vigente por medio de la figura del animero, y de la relación que tienen sus habitantes con los muertos que llegan a la orilla del puerto. En la década de 1980, la situación estratégica de este lugar sobre el río Magdalena ocasionó que los múltiples actores armados se enfrentaran por su control, lo que generó un alto número de muertos, muchos de ellos enterrados en el cementerio del pueblo como NN (proviene del latín nomen nescio, que significa "desconozco el nombre"). La adopción de los $\mathrm{NN}$ - un rito religioso con el cual buscan obtener favores del muerto-y el rito del animero, el de "sacar" a las ánimas del cementerio para no olvidar a sus muertos, contribuyeron a recrear y fortalecer en los habitantes del puerto unos hábitos religiosos identitarios. De esta manera, los porteños recrean su identidad colectiva apelando a los símbolos y rituales derivados de sus creencias y prácticas religiosas frente a la muerte, en una especie de hilo de la memoria religiosa e identitaria, como lo expresó, en su momento, Hervieu Léger (2005), para el caso de las identidades religiosas en la Francia laicizada del siglo XX.

Maurice Halbwachs (2004), a comienzos del siglo XX, ya había referido que la memoria colectiva permitía a las comunidades asumirse como tales y crear identidades afines a un pasado común; del mismo modo, este autor explica que las creencias religiosas son construcciones que estimulan el recuerdo, la rememoración y la identidad colectiva. En este caso, el animero, durante el mes de noviembre, cumple la función de recordarle a los porteños que sus difuntos están en el cementerio y que esperan sus oraciones, para así no ser olvidados.

En el análisis de la información recolectada, se tuvo presente cómo los actores sociales, al rememorar para no olvidar, sufren, resignifican y encuentran nuevas explicaciones frente al recuerdo (Ortega, 2011). La memoria no solo se comprende como un escenario de rememoración, sino como un dispositivo terapéutico de perdón; lo cual, de hecho, se presenta con toda claridad en las sociedades que han sufrido traumas colectivos y que están dispuestas a reconocer y comprender los hechos victimizantes, ello con el ánimo de hacer justicia y contribuir al perdón ${ }^{1}$. De igual manera, en la escucha de la rememorización terapéutica o de denuncia,

1. En Colombia, durante la primera década del siglo XXI, el debate sobre los usos de la memoria adquirió resonancia gracias a que las víctimas se organizaron e insistieron que en las rememoraciones deberían incluirlos pues, según ellos, es un deber moral de la sociedad reconocer las múltiples y terribles violaciones a los derechos humanos que han sufrido. La re-memorización no solo es comprendida como una terapia frente al trauma, sino que asume una función política tradicionalmente hegemonizada por las historias nacionales de los vencedores (Ricoeur, 2004; Rieff, 2017). 
también se requiere estar atento frente a los abusos de la memoria, al olvido o al ocultamiento de la verdad (Todorov, 2013).

Además, en la escucha de los testimonios se han tenido presentes los debates en torno a las dificultades de la historia oral como herramienta metodológica, pues se argumenta que la memoria es frágil y que el narrador tiende a modificar los hechos; en este sentido, interesa más comprender las subjetividades presentes en lo religioso que la veracidad de los mismos, importa más la narrativa religiosa. De ahí que esta investigación tuvo presente los argumentos alrededor de la memoria, la verdad y la justicia, pero centró su análisis en el estudio de la religiosidad popular (adopción de prácticas religiosas no institucionalizadas), representada en el animero. En este sentido, la memoria es usada para resignificar lo religioso, darle identidad a los muertos (NN) o rezarle a las "benditas almas", con el objeto de buscar su salvación u obtener un beneficio.

\section{Violencia y religiosidad}

El antropólogo Rene Girard (1983) -al explicar el origen de las religiones como expiación de la violencia- insiste en afirmar que esta se consagró por medio de sacrificios reparadores, dirigidos a resarcir el caos generado por los sacrilegios a los tótems o al orden cultural, muchas veces ocasionados por la afrenta a un miembro de la misma comunidad; de ahí que, en sus orígenes, la violencia haga parte de las prácticas religiosas (Geertz, 2009) ${ }^{2}$.

En un sentido similar, para el caso del cristianismo, una corriente teológica tradicionalista insiste en mostrar cómo su ética y su propuesta de universalidad no son opuestas a la violencia, y que esta se respalda por medio de la "guerra justa" (Sorge, 1978; Walzer, 1983). Además, esta tendencia afirma que los ritos de la muerte siempre estuvieron presentes en el Antiguo Testamento y que, en ocasiones, es necesario castigar a los herejes y a los paganos. Otros alegan que el origen de la ética del amor comenzó con un Cristo crucificado y redentor de la humanidad; que su sacrificio representa la salvación y el perdón divino (Baro, 2015; Pérez, 2014; Plata; Figueroa, 2017). En suma, el martirio, la flagelación y la sangre de Cristo representan el amor divino, presente en el sacrificio y la resurrección a la salvación. Es decir, un hecho violento se transforma, por medio de las representaciones sacras y los ritos

2. Rene Girard (1983), en su texto La violencia y lo sagrado, explica que los sacrificios religiosos, a pesar de ser violentos, lo que buscan es desviar los conflictos internos, restableciendo el orden. Un orden social que Clifford Geertz (2009) define como fundamental para organizar el equilibrio social y la cosmovisión de las comunidades. 
religiosos, en un hecho salvífico y de amor. La violencia y lo sagrado se realizan como justificación inicial frente al acto violento-transformado simbólicamente en salvación-o como acto de resistencia y esperanza frente a la muerte (Girard, 1983), como podría ser el caso de los creyentes de Puerto Berrío.

Recientemente, otras investigaciones sobre la relación religión-violencia afirman que hay nuevas perspectivas de análisis centradas en identificar cómo la violencia y lo sagrado comprenden una relación dicotómica, que se presenta "in the religious imagination, from symbols and myths to legendary battles, from colossal wars to the theater of terrorism." (Jerryson; Juergensmeyer; Kitts, 2013). No obstante, estas obras continúan apelando a los clásicos de los estudios de la religión, dado que sus conclusiones todavía tienen vigencia, en el sentido de que la humanidad encuentra en lo religioso un espacio sagrado de creación de sentido, claro, sin separarlo de sus otras esferas sociales, como insisten otros autores contemporáneos (Bellerose, 2009; Gauchet, 2004).

Ahora bien, para los historiadores Cifuentes y Figueroa (2004), la cultura colombiana y, en particular, sus tradiciones políticas y sociales no se pueden comprender en toda su dimensión sin tener presente la fuerza del catolicismo y su relación con las múltiples guerras civiles del siglo XIX, en la violencia de mediados del siglo XX y, por supuesto, en el conflicto armado de su segunda mitad; además, en relación con los procesos históricos y los espacios geográficos del país, dado que este fenómeno social se presenta en diferentes grados de simbiosis y profundidad, dependiendo la región.

Uno de los territorios que mejor sincretiza esta relación es Antioquia: por su conservatismo, catolicismo intransigente y por su alto número de religiosos presentes en múltiples comunidades y vocaciones religiosas (Londoño, 2004). En este departamento, las heterogéneas violencias conviven naturalmente con la religiosidad popular-entendida como una expresión ritual diversa que puede simbolizar creencias y prácticas religiosas no institucionalizadas-, protagonizada por los creyentes de forma autónoma y que la institución eclesiástica tolera o termina por cooptar, dependiendo de su masificación y posibilidad de explicación teológica (Marzal, 1997).

Una de las manifestaciones de religiosidad popular en la cultura antioqueña es el animero, un personaje que intermedia entre los vivos y los muertos, y que fue creado en el mundo colonial por los miembros de la Cofradía de las Ánimas del Purgatorio. Por medio de su práctica y devoción a las "almas benditas", el animero busca, colectivamente, la purificación y expiación de los pecados, en el tránsito a la salvación de los difuntos o de las culpas propias y ajenas de los habitantes de Puerto Berrío. Además, en escenarios de permanente violencia, donde la muerte acecha todo el tiempo, el rito del animero y su comunicación con las almas benditas se convierte en una opción de salvación y, hasta cierto punto, de naturalización de 
la muerte ${ }^{3}$. En este sentido, una hipótesis factible para esta investigación es que la religión opera como un escenario social que ayuda a superar, de alguna manera, la pérdida de sentido que ocasiona la muerte de un familiar, el ser víctima de un hecho violento; o también puede contribuir a organizar el caos (Geertz, 2009) que genera la culpa, sobre todo si el que la siente es un victimario.

En Colombia, la devoción a las almas del purgatorio ${ }^{4}$, al lado de un santoral diverso, se manifiesta, públicamente, en el mes de noviembre, mediante ritos sagrados y la devoción a los muertos, una práctica religiosa heredada de Europa, también presente en España, México y Ecuador's. Las creencias y ritos del animero se manifiestan en diversos municipios antioqueños, sobresaliendo Titiribí, Yolombó, Guarne, Marinilla, Copacabana y Puerto Berrío. Allí, en las noches de noviembre, los animeros recorren las calles de los pueblos, comenzando desde el cementerio, para pedir a los devotos padrenuestros y avemarías, con la finalidad de recordar a los muertos, implorarles favores y orar por los vivos.

El objetivo central de esta propuesta es describir y analizar cómo la tradición del animero, en Puerto Berrío, se ha transmitido de generación en generación, para dar sentido de vida, esperanza y reconciliación a una comunidad azotada por la violencia; es decir, se busca explicar cómo se mantiene en la memoria colectiva local la figura del animero y su ritual, en relación con la violencia generada por los múltiples actores del conflicto armado. La metodología utilizada para analizar este hecho social se basa en la realización de salidas de campo (entre octubre de 2013 y

3. Ciertamente, el ser humano y su cuerpo basan su existencia en una interacción continua del sujeto con otros cuerpos dentro de un espacio-tiempo determinado, lo que fija su identidad, una capacidad de reconocimiento de sí a partir del otro, y del otro a partir de sí mismo (Aguado, 2004). Sin embargo, con la muerte, el cuerpo del difunto se torna incapaz de ser frente al otro, a cambio, se convierte mágicamente en un recordatorio para los vivos de que la muerte existe. Como lo señala Louis-Vincent Thomas (1983): "la muerte en sí misma tiene un carácter intemporal y metafísico, pero deja siempre un cadáver actual y real. Es este aspecto orgánico de la muerte el que parece hacer olvidar a todos los otros, quizás porque toca más intensamente nuestra sensibilidad y también a la existencia misma del cadáver que es una expresión concreta por excelencia” (33).

4. La representación física del purgatorio (el lugar de las "benditas almas"), elaborada en el barroco, llegó a América para quedarse, gracias a las representaciones elaboradas por los pintores neogranadinos (Borja, 2010). En la Nueva Granada, al igual que en otros territorios del continente americano, además del impulso dado por los pintores del barroco, influyeron las cofradías y hermandades, siendo estas comunidades las que consolidaron la idea del purgatorio y de sus ánimas (López, 2005). En suma, la devoción a las ánimas del purgatorio, en Colombia, es una tradición que está incrustada en la religiosidad popular, por ser una manifestación ritual que incluye el ámbito de lo sagrado (Serna; Londoño; Aguirre, 2008), con manifestaciones sociales profundas frente a la muerte.

5. El ritual y sus elementos pueden contener diferencias entre uno y otro, sin embargo, el rol del animero es el mismo. 
mayo de 2014), donde se destaca la observación participante. También, se realizaron 18 entrevistas a sus pobladores y al actual animero, Hernán Darío Montoya Gómez. Un trabajo de campo contrastado con los escritos de los antropólogos Víctor Turner (1980) y Louis-Vincent Thomas (1983; 1991; 1992); además, un análisis enmarcado en la contextualización histórica y social de Puerto Berrío.

Contribuir a responder a los interrogantes generados a la hora de evidenciar la relación violencia-religión en Colombia, desde una perspectiva cultural, requiere todavía muchos esfuerzos investigativos, de ahí que las respuestas sean poco claras, difusas y escasas. Por ello, un acercamiento etnográfico a la práctica religiosa del animero puede aportar a comprender este hecho social. Por lo anterior, esta investigación espera ayudar a describir la cultura religiosa de una comunidad azotada por la violencia, con el objeto de aportar para llenar el vacío denunciado por Elsa Blair (2005) y Alejandro Castillejo (2016) -en relación con la falta de estudios en torno a la cultura-, y en la comprensión o, mejor, en la identificación de componentes simbólicos de la violencia.

Teniendo en cuenta estas precisiones conceptuales y metodológicas -en torno a la memoria colectiva y los usos de la memoria, la identidad religiosa, la relación entre religión y violencia-, el presente texto, inicialmente, se centra en presentar, de forma breve, características geográficas del municipio de Puerto Berrío, destacando las expresiones de violencia derivadas del conflicto armado (desarrollado a mediados de los años noventa y con antecedentes durante la década anterior) y su relación con tradiciones religiosas. Después, se describe la devoción a las ánimas benditas del purgatorio, en medio de la adopción de los NN que encallan en el puerto, mostrando los estudios y trabajos que han abordado el tema. Enseguida, se describe $\mathrm{y}$ analiza la función social del animero, su rito, su historia de vida y la forma como este es aceptado y reconocido por su significado religioso. Finalmente, se presentan y analizan las percepciones y prácticas de los porteños en relación con las anteriores prácticas religiosas, para concluir con tesis sobre la contribución que estas hacen a la memoria, la identidad y la vida comunitaria del municipio y la región.

\section{El municipio de Puerto Berrío, un cementerio}

El Magdalena Medio, primero bajo la presión de las guerrillas del ELN y las FARC, y luego con la llegada de los paramilitares, se transformó en zona de guerra, de desaparecidos y de centenares de muertos. Muertos sin nombre y sin tumba, por lo que el río Magdalena se convirtió en esta. Según cifras de la Asociación de Familiares de Detenidos-Desaparecidos (ASFADES), entre 1984 y 2003 se presentaron, en todo el país, 
6875 desapariciones forzadas, en las que se vieron involucrados grupos de izquierda, de derecha y el Estado colombiano. Para el caso del Magdalena Medio, un informe de la Corporación Regional para la Defensa de los Derechos Humanos (CREDHOS) revela que, entre 2000 y 2003, en esta región, se presentaron 208 desapariciones forzadas, 13 de ellas en Bolívar, 186 en Santander y 9 en Antioquia (Santos, 2013).

En este escenario de guerra, en Puerto Berrío, durante el período de 1985-2012, hubo 2932 muertes violentas, con un total de 9974 hechos victimizantes. El pico más alto de muertes violentas se presentó en el año 1992, correspondiente a 175 homicidios; y 618 hechos victimizantes, en 2006. Al comparar estas cifras con los promedios nacionales y teniendo en cuenta que su población es de 40 ooo habitantes, la tasa de homicidios, durante este período, fue aproximadamente cuatro veces superior al promedio nacional, que era de 85 homicidios por cien mil habitantes.

La ubicación estratégica de Puerto Berrío, así como el interés por parte de los grandes hacendados-ganaderos y de las élites políticas y económicas de la región para controlarla, fue el caldo de cultivo de esta guerra. Es así como, desde finales de los años ochenta, los paramilitares lo ocuparon, con el objeto de controlar militarmente el Magdalena Medio, como en efecto ocurrió. Desde Puerto Berrío, los paramilitares hicieron presencia hacia el sur, hasta Puerto Boyacá; por el norte, se consolidaron hasta Barrancabermeja, para continuar río abajo y llegar a los puertos marítimos de la Costa Caribe. Una estrategia militar basada en el terror armado y sanguinario que dejó cientos de muertos y desaparecidos, y miles de desplazados.

En este contexto, la ubicación portuaria del municipio creó la costumbre de arrojar al río los muertos encallados en sus orillas, para que desaparecieran. En Colombia, gran cantidad de ríos son utilizados para desaparecer los cadáveres y negar la memoria de las víctimas, como permanentemente se denuncia en los periódicos (Por siete ríos..., 2007). Es en este escenario fluvial donde se presenta la particular devoción a las ánimas, estimulada por el animero del puerto y por la adopción de los $\mathrm{NN}^{6}$. Los "muertos del agua" han sido adoptados por la comunidad para obtener un intercambio de favores: los vivos les dan nombre y apellido, les arreglan sus tumbas y les ponen agua, les otorgan identidad y conmemoran su recuerdo. Así lo expresa uno de sus habitantes:

Resulta que (...) eso se volvió difícil, antes llegaban muchos “muertos del río", entonces era fácil escoger, ahora uno habla con el sepulturero y le dice que le avise cuando haya

6. Existen varias investigaciones que han estudiado esta práctica, y de las cuales vale la pena resaltar la realizada por Julián David Rodríguez Camacho (2015), "Puerto Berrío: entre un cementerio de agua y una creciente de lágrimas". 
un "sin nombre" nuevo, y uno le da cualquier cosita a él por el favor. Uno nuevo tiene mucha efectividad, cierto... En cuanto lo escoges, le marcas sobre la bóveda que está escogido, así ya saben que está ocupado con uno. Cuando termina el favor se le cumple con lo prometido, sea la lápida o el cuidado de su tumba; solo en ese momento otra persona lo puede volver a escoger (Rosalba Muñoz, comunicación personal, 15.05.2014).

Claro está que la devoción a las benditas almas también es una forma de hacer duelo frente a los propios desaparecidos; por supuesto, una tradición anterior a la llegada masiva de los NN, como lo recuerda Ana Barrientos:

Mi hijo desapareció hace unos años, siempre he esperado su regreso, sea vivo o muerto. Cuando la gente cuenta que hay un muerto en el río, me esperanzo en que sea él (...). No sé si está muerto, de pronto sea un NN que más abajo alguien enterró, y de ser así, espero que tenga quien lo recuerde, aunque no sea suyo, mientras yo acá tomo uno como el mío, le pongo un nombre de hombre, en recuerdo de mi hijo, y lo trato como si fuera mío. Acá todos los vecinos, cuando había muerto en el río, nos enterábamos y estábamos a la espera si lo recogían o lo dejaban pasar. Antes de los muertos que llegaban por el río, en el pueblo solo orábamos por los nuestros (Ana Barrientos, comunicación personal, 18.11.2013).

Los NN son adoptados para rezarles a cambio de protección y ayuda en los diferentes problemas del nuevo doliente: "Cuando he adoptado un NN ha sido por pura necesidad: no tener trabajo, no tener plata (dinero) o, en todo caso, que no nos alcance; esas veces les he pedido con fervor, y me cumplen" (Antonio Aristizábal, comunicación personal, 12.11.2013). La adopción del muerto, en múltiples ocasiones, termina con el otorgamiento de identidad mediante la concesión de un nombre. Por orientaciones de la Fiscalía, estos no deben alterar su identificación de NN, por lo que los porteños optaron por ponerle nombres y apellidos con las iniciales N. N., así reconocen su condición de no nombrado.

Nombrarlos, darles identidad, es otorgarles memoria y crear un hilo entre el allá (espacio sagrado) y el acá (el mundo de los vivos, el profano). De esta manera, las benditas almas pueden intermediar y ser más efectivas. Sin una identidad, esta intermediación podría ser nula. En este sentido, como lo expresa Mercie Eliade (2016), la sacralización de los espacios profanos solo se puede realizar por medio de ritos que comuniquen el mundo profano con el sacro, y darle nombre es sacralizarlo; así, la comunicación con el alma bendita es efectiva. Para la comunidad, está claro que cada muerto solo puede tener un doliente mientras el alma intercede en el asunto terrenal, después se le deja a un nuevo doliente (Thomas, 1983). "No se 
puede escoger el mismo muerto a la vez. Porque, ¿qué tal llegue uno con más fe? Le deja el favorcito de uno tirado y se lo hace al otro. Debe ser uno por uno" (Abelardo Gómez, comunicación personal, 25.05.2014)7.

En el relato de Ana, llama la atención la observación de que no siempre se recogían los muertos. En efecto, durante la segundad mitad de los años noventa, cuando el conflicto armado arreciaba, el control de los paramilitares, en muchas ocasiones, impedía sacar a los muertos del río, pues estos debían cumplir la función de generar terror en quien los viera, pero también era una forma de que no tuvieran memoria ni nombre (Rodríguez, 2015).

Antes, cuando todos los días había muertos, la cosa era diferente... acá había quien diera órdenes, y si no permitían recoger el muerto que llegó a la orilla del río o que se enredó en la atarraya, tocaba dejarlo ir, empujarlo con un palito para que parara más abajo, en otro puerto (Jesús del Carmen Villa, comunicación personal, 27.05.2014).

Y es que, como afirma la antropóloga María Victoria Uribe:

En medio de ese ambiente de guerra profundamente deshumanizante, los rituales que se realizan con las ánimas sufrientes de los N.N. en algunos cementerios colombianos ponen en evidencia que la reparación colectiva pasa por reincorporar al tejido social a los muertos anónimos que han sido condenados al olvido. El animero, la devoción popular y la obligación moral de aliviarle el sufrimiento a las ánimas son los elementos a partir de los cuales los habitantes de Puerto Berrío contravienen el mandato de desaparición y olvido decretado por los perpetradores de la violencia, construyendo nuevos significados que transforman el horror de la guerra (Uribe, 2008: 184).

Vale la pena resaltar que la adopción de los muertos es un elemento fundamental en la religiosidad popular porteña, por ello esta temática ya ha sido usada para explicar las dinámicas del conflicto armado, por parte de académicos y artistas. Por ejemplo, en el año 2012, Patricia Nieto (2012) publicó el libro Los Escogidos, un texto de corte periodístico donde la autora teje diálogos de los porteños que reconstruyen la memoria de sus habitantes y ponen en evidencia su religiosidad. Posteriormente, en 2015, Julián David Rodríguez Camacho (2015) culminó su maestría en estudios culturales con la tesis "Puerto Berrío. Entre un cementerio de agua y una creciente de lágrimas: dimensiones sociales, políticas y culturales de las prácticas funerarias en el conflicto armado". Finalmente, en el año 2017, se estrenó la propuesta artística de

7. Varios entrevistados relatan anécdotas de discusiones y peleas dadas en el cementerio por no respetar el letrero de escogido puesto en la bóveda. Ellos creen que se disminuye la efectividad si hay más de un fiel pidiendo por sus necesidades. 
Juan Manuel Echavarría, titulada "Réquiem NN", donde se recogieron fotografías, videos y un texto audiovisual que narraba la religiosidad popular del municipio. Respecto a esta producción, el curador de la obra y comentarista, Elkin Rubiano, afirma:

Réquiem NN está conformada por tres obras: una serie fotográfica (2006-2015), 12 videos con el título Novenarios en espera (2012) y un documental (2013) de 70 minutos. En la serie fotográfica, se hace un seguimiento de la adopción de los NN mediante un registro tomado en dos o más tiempos. Entre una imagen y la otra, se logra ver la intervención que las personas hacen en la sepultura: las inscripciones, las flores, las imágenes sagradas, los favores pedidos y las gracias por los recibidos. En Novenarios en espera, se utiliza el mismo recurso, aunque con imagen en movimiento. El documental da un paso más, pues no se queda solo en el registro de la transformación de las bóvedas, sino que articula la práctica de la adopción de los NN con el relato de sus protagonistas: el forense, el sepulturero, los adoptantes y solicitantes, etc. El hecho de que en Puerto Berrío se adopten cuerpos no identificados ha dado pie para que tal práctica se interprete como una forma de resistencia contra la eliminación de la identidad de las víctimas. Esa es la opinión del propio Echavarría: La gente de puerto Berrío no permite, quizás inconscientemente, que los perpetradores de la violencia desaparezcan a sus víctimas. Mediante este rito es como si ellos les dijeran a los victimarios: Aquí nosotros rescatamos a los NN, los enterramos, creemos en sus almas, y nos hacen milagros; además los adoptamos y los volvemos nuestros (Rubiano, 2017:38).

Como se observa, la mayoría de los trabajos reseñados se han ocupado de estudiar la adopción de los NN, pero no directamente de la devoción a las benditas almas, una creencia que podría ayudar a explicarla, siendo una práctica religiosa acentuada por la figura del animero, dado que este se encarga de recordarles a los devotos que en el cementerio hay nuevos muertos que requieren ser orados. Es esta última tradición el objetivo principal del presente texto. Al respecto, en las entrevistas a los porteños que tienen familiares desaparecidos, ellos manifestaban que, al ver al animero en la misa de los lunes-dedicada a las benditas almas y que se realiza en el cementerio- ${ }^{8}$, recuerdan su compromiso de llevarles agua y arreglarles las tumbas a los NN adoptados; así lo expresaba uno de los entrevistados: "Cuando uno ya se compromete con ellas, hay que estar muy pendientes de ellas y estar invocándolas todos los días. Además de que uno les tiene que cumplir lo que les prometió, porque si no lo joden a uno" (María Helena Jiménez Moreno, comunicación personal, 09.11.2013).

8. En relación con los cementerios y el culto a las ánimas del purgatorio, para Colombia existen varios trabajos antropológicos que comprenden al cementerio como un lugar de la memoria sagrada, en su versión mágico-religiosa y de representación, y el significado de los difuntos en diferentes esferas como la política y cultural (García, 2015; Peláez, 2001). 


\section{El animero, una salida a la muerte}

En Puerto Berrío, la veneración a los NN ha sido una práctica que tuvo su auge en los momentos más crudos del conflicto armado, contribuyendo a fortalecer la devoción a las almas del purgatorio, lo cual, a su vez, renovó la creencia tradicional en el animero. Con estas prácticas, los devotos porteños resisten al olvido de los muertos y se solidarizan con el fallecido, al devolverle parte de la humanidad arrebatada frente a su muerte violenta y, de paso, pedirle favores. Como lo expresa Hugo Hernán Montoya:

Vea... la tradición del animero no ha estado todo el tiempo, han existido épocas sin animero, pero desde hace unos años se ha mantenido constante. El animero es quien recuerda a los muertos y les recuerda a los vivos la necesidad de que los recuerden, que les recen y que estén ahí para ellos, porque ellos están ahí para los creyentes (Hugo Hernán Montoya, comunicación personal, 20.02.2014).

Hugo Hernán es el animero de Puerto Berrío, tiene 63 años de edad, trabaja arreglando jardines y, como él mismo lo expresa, "en lo que salga". Según su testimonio, su función como animero comenzó gracias a su experiencia religiosa con las ánimas del purgatorio. Él cuenta que, desde su nacimiento, estuvo encomendado a San Nicolás de Tolentino, patrón de las ánimas del purgatorio y abogado de ellas (Hugo Hernán Montoya, comunicación personal, 20.02.2014). Este santo intercedió en su salvación a través de las oraciones de su tía, a quien se refiere como tía-madre, mientras recuerda que ella lo auxilió cuando era un bebé sietemesino, descuidado por su madre. Por consejo del párroco del pueblo, ella hizo la novena y compró los bizcochuelos de San Nicolás, para dárselos mojados con agua bendita, con lo que logró su pronta recuperación.

Hugo Hernán reconoce haber sido drogadicto y violento; sin embargo, al recuperarse de la drogadicción se convirtió en el animero del pueblo. Recuerda que también fue víctima de un atentado, al ser identificado como expendedor de drogas, situación que lo puso en la mira de sectores de la sociedad porteña, patrocinadores de la "limpieza social" y que dieron órdenes de matarlo, sin importar que ya fuera el animero. Cuenta que, en varias oportunidades, fue amenazado por ello y en una madrugada recibió "cuatro disparos a quemarropa que no lograron impactar su cuerpo", lo que dejó al atacante estupefacto. Al día siguiente, según cuenta, el agresor lo buscó para preguntarle cuál era la oración que lo protegía para evitar la muerte. Ante este interrogante, Hugo Hernán le respondió: "Lo que yo hago es encomendarme a Dios, nuestro señor, y a las almas del purgatorio", a lo que el atacante replicó: "Entonces vos quién sos, porque yo ayer te tire a matar"; y el animero respondió: 
"Vea mano, vea, el que necesita protección es usted, yo la tengo. Yo soy el animero de este pueblo".

Con este testimonio, expresa su devoción y su relación con las almas, en un escenario de guerra donde la muerte está a la vuelta de la esquina y es natural hablar de ella, máxime si la misma sociedad que le pide favores a los muertos considera normal matar a los indeseables y no es mal visto organizarse para la limpiar la sociedad de ellos. Pareciera que esas prácticas de rememorización no eran bien vistas por los grupos paramilitares, pues ese acto iba en contra de su propósito de hacer olvidar, o se convertía en un aliciente de esperanza para las comunidades que se oponían al terror paramilitar. Pero otra podría ser la interpretación: "iSi hay más muertos a quien rezarle!", dijo un porteño, cuando el equipo de investigación inquiría sobre esta práctica al momento de la llegada de los paramilitares.

El animero decidió mediar entre los vivos y los muertos de su pueblo, en medio de la violencia que lo azotaba, porque era devoto a las ánimas del purgatorio, porque era "católico, apostólico y romano" -como insiste permanentemente al preguntarle por su filiación religiosa- $y$, además, porque no le tenía miedo a los difuntos, como se lo argumentó al sacerdote Pedro Claver, cuando este lo confrontó para solicitarle que dejara de ser animero. Según Hugo Hernán, al final el párroco le dijo que buscara un atuendo más adecuado y, con la aparente aprobación sacerdotal, acudió a la comunidad para para adquirir la capa, el sombrero, los guantes, dos camándulas (una para ponerse y otra para llevar en la mano), las botas, la copia de las llaves del cementerio (porque el sacerdote no sabía quién las tenía) y la campana del asilo de ancianos. Este acontecimiento ocurrió, según Hugo Hernán, en el año 2000, en uno de los momentos más violentos que sufría la región: la expansión paramilitar. "Cuando la gente del pueblo supo que volvía el animero, se alegró mucho, porque en esos días había muchos muertos. La gente tenía como miedo y andaba con muchos problemas" (Hugo Hernán Montoya, comunicación personal, 20.02.2014).. Desde ese entonces, todos los 2 de noviembre, Hugo Hernán inicia su ritual de adoración a las benditas almas del purgatorio. En 2013, cuando el equipo de investigación participó durante varias noches de este ritual, el del animero se desarrollaba de la manera que se narra en los párrafos siguientes.

Al llegar al cementerio, sitio de donde comienza su camino, a las once de la noche, el animero encuentra algunos devotos que lo acompañaran, pero advirtiéndoles que si no son creyentes no lo sigan. Después de esto, él viste su atuendo, un aspecto central del rito y que, según él, tiene las siguientes funciones: 1) distinguirse del resto de los devotos, atemorizar simbólicamente a la comunidad, tapar la visibilidad hacia atrás (donde lo siguen las ánimas) y evitar el frío de las ánimas; 2) la campana es para hacer el llamado a las ánimas y guiarlas por el camino y, a su vez, despertar a 
la comunidad para que rece el padrenuestro y el avemaría; 3) los guantes y las botas tienen la función de protegerlo del clima y del frío de las ánimas; y 4) el novenario y las camándulas son ofrecidos a San Nicolás de Tolentino. Con estos elementos, se convierte en animero. "El señor que hace la labor de animero solo lo es con el atuendo. Cuando se viste en noviembre para salir por el pueblo con las animas él es su líder: les guía su camino, y les ayuda a recoger oraciones para salir del purgatorio" (José Giraldo, comunicación personal, 09.11.2013).

Al comienzo, todavía en el cementerio, el animero realiza una oración en ofrecimiento a las ánimas del purgatorio; en la capilla empieza el novenario, proceso en el cual va haciendo el llamado a las almas para que lo acompañen y, siendo aproximadamente las doce de la noche, sale del cementerio acompañado de los vivos y de los muertos. Sin importar el clima o su salud, el animero debe hacer el recorrido durante todas las noches del mes de noviembre. En la puerta del cementerio, listo para comenzar a caminar, pronuncia la siguiente oración:

De este pio campo santo las saco, y a este mismo pio campo santo vuelvo y las traigo. Que Dios nuestro señor y las benditas almas del purgatorio nos amparen y nos favorezcan de todo mal y peligro, en este recorrido de peregrinación por un padrenuestro y avemaría para las almas. Amén (Hugo Hernán Montoya, comunicación personal, 20.02.2014).

La estructura del ritual, después de salir del cementerio, es caminar por el pueblo, iniciando un segundo rosario y, simultáneamente, cada cierto tiempo, el animero toca la campana y reza un padrenuestro y un avemaría, por la benditas ánimas del purgatorio y por amor a Dios. Él da inicio al recorrido por el municipio sin tener un orden predeterminado, llegándolo a recorrer, en su totalidad, varias veces. En la época más fuerte de la violencia y cuando más muertos pasaban por el río, él hacía su recorrido con poca gente y en silencio, así lo recuerda una devota: "Al animero no le hacen nada, a él lo respeta toda la comunidad, no importa si es de los buenos o de los malos" (Gabriel Zapata Caicedo, comunicación personal, 07.11.2013). Durante los recorridos que se hacen acompañando al animero, se observan las calles semivacías, oscuras, llenas de huecos y a medio hacer; las luces apagadas de las casas representan el silencio del pueblo, pero todos los participantes de la procesión imaginan que sus moradores están escuchando las oraciones a los muertos y que responden con avemarías. No deben asomarse a la puerta. "En una ocasión, una muchacha salió a 'rendijiar' y cayó desmallada, ella dice que vio a las ánimas y sintió un escalofrió por todo su cuerpo" (Gabriel Zapata Caicedo, comunicación personal, 07.11.2013).

En las casas oran por las almas de sus difuntos, con la esperanza de que estén descansando y escuchen sus peticiones para conseguir trabajo, que se cure el enfermo, 
encontrar pareja, que el marido deje de tomar, que se resuelvan los problemas de la casa. Los acompañantes del animero oran por lo mismo, pero con más intensidad, pues creen que por acompañarlo sus rezos serán más efectivos. Las caras difusas de los devotos, en medio de la noche, muestran su devoción, mientras que las de los incrédulos están a la expectativa ${ }^{9}$. El animero, siempre ensimismado en sus rezos, camina ceremonialmente en una actitud contemplativa, entregado con devoción a su rito. Poco a poco, transita por el pueblo con la esperanza de que sus rezos lleguen a todos los deseosos de un favor de las ánimas. Acompañar al animero es una práctica relativamente nueva, pues antes iba solo. Una de las devotas explica por qué sale y qué espera:

Yo antes no salía a la procesión, pero desde que Hugo Hernán esta de animero siempre lo hago. Recuerdo que al comienzo lo hacíamos las vecinas de la cuadra, porque por esos días estaban matando mucha gente y esperábamos que si salíamos con el animero las benditas almas nos iban a ayudar a que no siguieran matando gente. Al comienzo como que no pasaba nada, pero de un momento a otro dejaron de matar gente, ya no había tanto muerto para enterrar en el cementerio, de esos que bajan por el rio (...). Yo tuve varios enfermos en la familia que desde que comencé a salir se curaron. Y soy muy creyente de las benditas almas, mis hijos como ya no creen, pero yo les pido a las benditas almas que los cuiden (...). El recorrido dura como dos horas, yo me las patoneo porque hay que acompañar al animero para que no quede solo, ahora como que hay mucha gente que no cree y pues toca ayudarle (María del Pilar Salteño, comunicación personal, 07.11.2013).

A otras personas del pueblo les parece extraño que la gente salga a acompañarlo $y$, en cierta forma, se lamentan por que se ha perdido la fe o el respeto por este rito:

Cuando yo era niño y escuchaba al animero me tapaba con la cobija hasta la cabeza, y rezaba las aves marías. Cuando iba con mi mamá y se encontraba con el señor que era animero no lo miraba a la cara, a pesar que era un vecino. Hoy veo a don Hernán y cómo interactúa con las personas y las personas con él, y me parece extraño: le hablan directamente, le miran a la cara e, incluso, salen con él en sus recorridos (Oscar Hurtado, comunicación personal, 21.05.2014).

9. Actualmente, es muy difícil conocer hasta dónde hay una devoción a este rito o solo curiosidad hacia las almas del purgatorio; sin embargo, la misma comunidad denota una transformación en el ritual hacia cierta banalización. 
Al finalizar dicho recorrido, el animero vuelve al cementerio, donde culmina su ritual con la oración: "De este pio santo campo las saqué, y a este mismo pio santo campo vuelvo y las dejo. Amén". Generalmente, este proceso dura entre dos o dos horas y media. Al terminar, se quita el atuendo y vuelve a su casa. Este ritual dura 27 días y, el 30 de noviembre, en el cementerio, se hace una misa en las horas de la noche, con una novena y el rezo del rosario ${ }^{10}$.

Al culminar este rito, el equipo de investigación-que participó durante varios días en él-se preguntó si los asistentes a la procesión y quienes respondían a las plegarias del animero con avemarías tenían las mismas razones-o parecidas-a las expresadas por él, quien, al interrogársele sobre por qué cree en las almas del purgatorio, es reiterativo en afirmar que su creencia en ellas se debe a los favores recibidos:

Yo me decidí por una devoción de nosotros (...), por muchos favores que las almas del purgatorio me han hecho a mí (...), pa pedir por aquellas personas que me dicen: "Animero, pídale a las almas del purgatorio que me alivien" (...), por aquellas almas que no tuvieron una sagrada sepultura. Entonces yo le pido a Dios, nuestro Señor, por esas almas (...). Me metí de animero era porque ya ellas me habían hecho muchos favores. Entonces yo dije: "Yo tengo que pagar esos favores, intercediendo por ellas ante Dios, nuestro Señor, y ante San Nicolás de Tolentino" (...), para que todas aquellas almas que estén sedientas (...), que no haigan tenido una sagrada sepultura, aquellas almas que estén más al borde del abismo infernal (...), para que Dios las salve. Entonces, por eso fue que yo me metí de animero (Hugo Hernán Montoya, comunicación personal, 17.09.2011).

Hugo Hernán es una persona humilde y sin educación, que durante el mes de noviembre se transforma en un personaje reconocido por su comunidad. En efecto, su insistencia en afirmar que fue favorecido por las almas del purgatorio y que esto lo obliga a prestar este servicio lo convierte en un personaje respetado y querido por sus paisanos. Pasado el mes de noviembre, Hugo Hernán vuelve a ser un habitante más del pueblo, que lucha por sobrevivir con sus múltiples actividades del rebusque "en lo que salga".

10. El ritual del animero, al parecer, es estructuralmente similar en los diferentes municipios de Antioquia; sin embargo, son las experiencias colectivas y personales las que cargan de manera diferente la simbología expresada, siendo la comunidad, en general, la que adopta una posición, positiva o negativa, frente a esta práctica. 


\section{Esperanza y reconciliación en los creyentes}

La tradición del animero da sentido de vida, esperanza y reconciliación, a través de la memoria y la oralidad que, encabezadas por los adultos mayores, consolidan la memoria local de este personaje y su ritual. Ellos han sido quienes, a través de sus historias, mitos y explicaciones, han creado un imaginario de respeto y apoyo hacia el oficio del animero. Recuerdan en sus historias la devoción que se le tenía a este personaje, al realizar desinteresadamente una labor vertebral para la localidad y para todos los que tenían familiares que habían muerto y que podían manifestarse como ánimas. Así lo expresa Alicia Villa, mujer de 80 años y ferviente católica:

En aquella época, cuando yo era niña, uno veía el animero y le tenía mucho respeto, se escuchaba pasar y uno se escondía y rezaba, él era encomendado para realizar una labor escogida, no cualquiera podía ser animero y él merece mucho respeto (...). Con las ánimas no se juega (Alicia Villa, comunicación personal, 16.11.2013).

La perdurabilidad del ritual del animero se hace evidente por la fuerza identitaria que posee, para la comunidad porteña. En las procesiones de noviembre y en las fiestas religiosas de todo el año, junto a la devoción a Nuestra Señora de los Dolores, la figura del animero es motivo de orgullo y celebración. Se puede afirmar que la adoración a las benditas almas (de los muertos del pueblo y de los foráneos) $\mathrm{y}$ las funciones del animero son una representación religiosa que le da identidad al pueblo, como lo reitera Alicia: "aquí todos los porteños somos devotos a las benditas almas, siempre nos han ayudado, en las buenas y en las malas"; mientras otra feligresa reitera que "en el pueblo siempre hemos sido muy creyentes, muy católicos".

En Puerto Berrío, el animero se ha configurado a través del recuerdo sacro, pero también de las habladurías en torno a los tres últimos animeros. El primero de ellos es Alonso Villa ${ }^{11}$, el cual es descrito como un hombre involucrado en la vida religiosa que, desde pequeño, prestó el servicio de acólito y tenía el anhelo de ser sacerdote. Francisco Villa, hermano de Alonso, cuenta que: "Mi hermano tenía por ahí... ¿qué? (...) 16 años, y duró como animero unos diez años. Ese inicio fue para el 1972. Él lo hacía con mucha fe, más que muchos que lo han sido. A él le gusta mucho el culto a las ánimas". La gente de más edad y que tienen algún recuerdo de este personaje lo muestra como el último animero que realmente era religioso y no tenía mancha, una situación que contrasta con los dos más recientes, por su pasado de dudosa reputación, más cercanos a la "delincuencia y a los vicios". En este sentido, sus oficios

11. Aunque se intentó entrevistar a Alonso Villa, no fue posible; sin embargo, se habló con un hermano y una hija. 
religiosos (no institucionalizados) los redimieron para convertirse en representantes de una religiosidad popular en apariencia homogeneizante y reparadora.

El segundo animero, que ejerció su oficio en la década de 1990, no es recordado positivamente, por el contrario, los pobladores insisten en mostrarlo como un joven delincuente, con muchos vicios. No mencionan el nombre, pero afirman que lo mataron siendo animero y por ello fue el culpable de la mala reputación adquirida por el personaje en esos años. Él, precisamente, ejerció su labor cuando el conflicto armado estaba en su mayor intensidad. Rafael Ángel Hoyos lo recuerda, y recalca que este personaje puso en crisis la labor del animero e irrespetó las costumbres del pueblo: "La llegada de este animero fue como un momento de crisis y la gente como que tenía mucho miedo, nadie quería hacerse cargo de esa tarea, porque era peligroso por esos años salir de noche". Sería muy interesante analizar el significado de este cambio en la figura del animero y cómo la violencia afectó el oficio; infortunadamente, los testimonios recogidos no permiten hacer tal análisis, pero se intuye que, en efecto, hubo un momento de crisis ante la tragedia que se estaba viviendo en el Magdalena Medio. Pareciera que solo quienes delinquían podían estar cerca de la muerte, cerca de las benditas almas, "no hay que tenerlo miedo a la muerte, a los difuntos y menos a las benditas almas", reitera Hugo Hernán.

Por estos años, el otro animero que reconocen los porteños es el actual, Hugo Hernán Montoya, un personaje que, por su pasado, también es cuestionado por algunos habitantes; no obstante, por su constancia, deseo de superación y compromiso con su oficio, Hugo Hernán ya es aceptado por los habitantes del pueblo. Ante la ausencia de una institucionalización de la labor del animero, esta solo se ratifica colectivamente por el favor de los porteños. Además, como ha quedado evidenciado, la persona que encarna el animero se desdibuja por la fuerza histórica y socio-religiosa que adquiere al asumir su rol sagrado; es decir, este personaje se configura socialmente como sagrado, gracias al ritual llevado a cabo cada año en el mes de noviembre, lo que le permite envestirse de un carisma mágico.

Dentro de la amalgama de sensaciones que ofrece la creencia en el animero y su devoción, se destaca la curiosidad de verlo durante el desarrollo del ritual; por ello, los adultos mayores enseñan a las nuevas generaciones que no se debe ver a la calle cuando el animero pasa frente a la casa, porque las ánimas asustan a quien las vea. Aun así, la curiosidad de verlas en ocasiones se transforma en esperanza: se conocieron algunos casos donde personas adultas desean ver por la ventana, en busca de sus familiares desaparecidos y fallecidos. Luz Amparo afirma que no se aguantó las ganas de buscar a su hijo entre las almas que pasaban: 
A mí me han enseñado que no debo ver por la ventana cuando pasa el animero, que uno debe responder el rezo desde la cama, pero yo quería ver a mi hijo (fallecido), así que salí a observar. Él iba solo. No lo vi, pero me reconfortó imaginar que allí iba con las otras almas que yo no veía, pero que iban detrás del animero. Siempre les rezo a las benditas almas para que cuiden a mi hijo, también les rezo para que mis otros hijos estén bien, para que mi familia esté bien. A veces pienso que, si lo hago más seguido y con más devoción, ellas me escucharán, por eso cada vez que veo al animero tengo esa esperanza, como me lo enseñó mi madre (Luz Amparo Loaiza, comunicación personal, 15.11.2013).

La transmisión oral de esta creencia permite que esta devoción no se pierda en el tiempo: los abuelos y padres recuerdan que en el pueblo siempre se hizo. Hasta hace unos pocos años, el animero hacía el ritual de manera individual, ya que en ello influía la creencia de que detrás de él iban las ánimas y que no había que verlas. Actualmente, se realiza de manera grupal; los devotos y curiosos son libres en la decisión de acompañarlo. Para el creyente, estar en el ritual significa estar cerca del ánima que canaliza su rezo, lo que provee una experiencia personal y ocasiona peregrinaciones; para el no creyente, el ritual es asociado con un espectáculo:

En una ocasión que me fui a acompañar al animero, mi mamá me dijo: "Si va a ir hágalo con fe". En ese momento yo me estaba presentando a la universidad y estaba pidiendo ser admitido. Fue molesto ver amigos de la cuadra tomar el rito como un chiste, cuando muchos de los que lo acompañamos llevamos una petición que transformaría nuestra vida (Jorge Castrillón, comunicación personal, 05.11.2013).

A veces, para algunos participantes es un espectáculo que puede demostrar cierto descreimiento, pérdida del sentido religioso y banalización del rito. La cercanía al ritual e identificación con él hace que los habitantes crean, y tal vez para los foráneos solo sea una experiencia folclórica, como lo destaca Jeimy Zapata, de 16 años:

El animero es chévere, él nos hace sentir curiosidad y miedo. Con algunos amigos de la cuadra el año pasado nos organizamos para ir con él a pasear las ánimas. Iba mucha gente, algunas rezaban, y como nos reíamos, nos regañaron. Pero nosotros creemos, después rezamos para pedir perdón por las risas, porque nuestras mamás dicen que con las ánimas no se juega (Jeimy Zapata, comunicación personal, 13.11.2013).

De igual manera, la visión del animero, desde afuera, se ha popularizado en las primeras décadas del siglo XXI, a través de notas periodísticas escritas o reportajes audiovisuales (entre 2012 y 2018), en medios internacionales, nacionales y locales, 
como la BBC (Cosoy, 2017), El Tiempo (En Puerto Berrío..., 2006), W Radio (BBC, 2017), El Colombiano (Hoyos, 2014), Testigo Directo (Poveda, 2012), entre otros; donde también se incluyen versiones de las personas foráneas que, gracias a los dispositivos tecnológicos más populares, logran grabar o tomar fotos a la procesión del animero. Esta transición de la lógica ritual molesta a los creyentes, por lo que es repetitiva la queja recibida por parte de ellos o de los ancianos, afirmando que se ha perdido el respeto que se debe a esta tradición, pues "ahora forman algarabía al verlo y no hacen lo debido" (Gabriel Zapata Caicedo, comunicación personal, 07.11.2013). Al respecto, Alicia Villa agrega que:

Hoy en día, usted, por ejemplo, a las 11:30 p. m. está saliendo de su casa y se va (al cementerio). Claro que usted se queda acá donde dan la eucaristía (entrada del cementerio), y el animero le dice a usted: "Espéreme aqui", y él solo da la vuelta por el cementerio. Entonces ya usted sale con él rezando. Van cantidades de personas, esos que van atrás no van sino a mamar gallo (molestar), a tocar las puertas, a tirar piedras: van de recocha. Entonces ese respeto se perdió, no es como yo me crie cuando era niña (Alicia Villa, comunicación personal, 16.11.2013).

Bajo la perspectiva de los creyentes, es a través del animero que las ánimas tienen la posibilidad de ser "aliviadas". Y desde la comunidad en general, donde se mezclan otras creencias religiosas, se demuestra cómo este ritual, a través de los años, ha sido acogido y perfilado como un aspecto central en su vida, siendo constantemente resignificada su labor y generándose una serie de mitos que lo ratifican como elemento constitutivo de la cultura porteña, así como una forma de resarcir la muerte violenta que los acecha y con la cual aprendieron a convivir. Al conversar con la comunidad sobre la percepción del animero y su influencia en sus vidas, se hacen reiterativas estas posiciones. Así lo expresa María Helena:

El animero es un señor que puede ser diferente, lo que importa es lo que representa. Cuando era pequeña, mi abuela nos decía que si no hacíamos las cosas llamaría al animero, e inmediatamente salíamos corriendo con mi hermano. Ahora que soy mayor veo que no puedo pensar el municipio sin su presencia, a pesar de la cantidad de muertos que llegan por el río. Cuando murió el anterior al que está ahora y el pueblo se quedó sin él, se sentía la angustia al ver que se acercaba noviembre y nadie tomaba su posición por miedo (María Helena Jiménez Moreno, comunicación personal, 09.11.2013).

Igual piensa Rafael:

Nosotros acá somos animistas, le tenemos más devoción a las ánimas del purgatorio que, inclusive, a la Virgen María u otros, así que el animero es muy importante en nuestra 
vida, y no solamente en noviembre, nosotros lo buscamos cuando hay un muerto en la casa, para encomendarle oraciones y novenas, que nos ayuden a rezar, ya que ellos están tan cerquita de ellas (Rafael Ángel Hoyos, comunicación personal, 10.11.2013).

Es tan fuerte el arraigo que tiene la figura del animero que quienes consideran que dejaron de ser católicos todavía sienten respeto por todo lo que significa esta tradición para los porteños:

Yo no soy católico, hace tiempo dejé de serlo (...), aún ahora cuando escucho las campanas y la voz del animero me asomo a verlo, es gracioso ver su ropa y la manera de caminar. Yo no creo en eso, pero es agradable ver cómo alguien saca tiempo de su vida para hacer algo que lleva muchos años acá. Mis abuelos, mis padres y ahora yo con mis hijos, les cuento historias de lo que significa tenerlo, no en lo religioso, sino en lo social, como cuando uno habla con personas de otros sitios y les digo que nosotros tenemos animero y se quedan con la boca abierta, no saben qué es ni cómo se come, como diríamos acá, en esos momentos me siento bien de tener algo que nos represente (Gabriel Zapata Caicedo, comunicación personal, 07.11.2013).

Los entrevistados, al momento de narrar esta experiencia, lo hacen con voz imperativa y vehemente, se muestran felices y orgullosos de compartir la importancia del animero; inclusive más que su afinidad hacia la práctica religiosa, pues, en muchas ocasiones, pesa más la identidad cultural de los porteños. En este escenario, se rompen las barreras religiosas, sobresale la identidad social, su orgullo por la práctica y, si bien se le excluye su carácter religioso -como se percibe en el último testimonio-, se resalta la trayectoria familiar de los relatos alrededor de él. En definitiva, el rito religioso comunitario en torno al animero permite a los porteños resignificar su simbolismo, lo toman como suyo, lo ven y representan desde su afinidad religiosa, social y cultural, lo vuelven un referente identitario.

\section{Conclusión}

El rol de la religiosidad de los colombianos se manifiesta en las diversas violencias del país, como justificadora de las mismas o como un dispositivo de esperanza reparador. Esta devoción es vista como un medio por el cual los victimarios afirman tener la verdad y, en el caso de las víctimas, opera como un dispositivo de reparación: se vislumbra como un camino creador de sentido, de esperanza y, en los casos de las muertes violentas, de resignación de los deudos. De esta manera, la religión, la violencia y la memoria toman significados -y papeles-, variados y entrecruzados. 
Por ello, afrontar comunitariamente las realidades sociales derivadas de las muertes violentas requiere una comprensión colectiva de sus causas, para, de esta forma, asumir el duelo. Así ocurre en Puerto Berrío, pues, allí, la comunidad encuentra consuelo, sin distinciones ni marginalización, pero con la sensación de que lo sucedido es un designio divino, solo amainado por los ritos del animero y los favores pedidos a las benditas almas. En igual sentido, el funeral, el enterramiento o la visita al cementerio logran crear un rito de paso que pone a los muertos en lo trascendente y deja a los vivos con la expiación. Mircea Eliade (2016) explica cómo las expresiones simbólicas o materiales se cargan ritualmente de religiosidad y a través de ellas se manifiestan los sentimientos frente a la muerte.

Un ejemplo de ello es el afianzamiento, en la creencia, del animero, y su asignación de nuevos valores como respuesta a los procesos violentos. La comunidad asume una simbología cargada de sentido popular, diferente a la que le fue otorgada en la época colonial. Actualmente, el símbolo del animero puede ser diferente en cada sociedad donde está presente; particularmente, en Puerto Berrío, se expresa de forma comunitaria en la esperanza de los porteños de comunicarse con sus familiares desaparecidos o muertos (violentos, naturales o adoptados). La apropiación o recordación que hace el animero, por medio de sus oraciones y rito a los muertos, impide el olvido de su fallecimiento ${ }^{12}$, no permite la muerte social y, con ello, una vez más, en un contexto familiar, local y comunal, se rescatan sus memorias, historias y narrativas que hilan los recuerdos, las conmemoraciones y las reconciliaciones.

La permanencia del animero se logra por medio de los abuelos que recuerdan a los pequeños, durante el mes noviembre, la importancia de este personaje para el pueblo. Una tradición que se refuerza con las muertes violentas, como con los NN que trae el río Magdalena o con la desaparición de sus habitantes. La violencia fortalece la devoción a las ánimas del purgatorio, recreando una memoria colectiva e identitaria de la población porteña, en el sentido de que los NN los proveen de nuevas almas para adoptarlas; además, el animero les recuerda a los porteños la existencia de esos desconocidos, y estos, a su vez, la dureza del conflicto. A pesar de que el objeto de esta investigación es estudiar la simbología religiosa del animero y su mediación con las benditas almas, se percibe que la tradición de adoptar los NN, por parte de los porteños, contribuye a recrear la memoria de los muertos y, de esta manera, a fortalecer su identidad frente al protagonismo del animero.

Resulta interesante cómo la religiosidad popular sobre las ánimas del purgatorio es tan fuerte en la comunidad que, incluso, se mantiene por encima de la institución católica que, en ocasiones, ha querido desprenderse de la creencia. A su vez,

12. En caso de los desaparecidos esta expiación es imposible, pues no hay certeza de su muerte. 
sorprende que dos de los animeros más recientes hayan sido objeto de atentados, el primero murió y el segundo sobrevivió a uno para testimoniar sobre su salvación, una consecuencia, según él, de su devoción a las ánimas. Al analizar la vida de estos animeros, se descubre su origen humilde y sus experiencias de vida, cargadas de pobreza y exclusión, así como su situación de víctimas de la violencia del puerto, aunque no es posible saber esto es consecuencia de su función como animeros o se deriva del contexto de la región. Sin embargo, la religiosidad popular se convierte en una respuesta frente a la violencia vivida por todos los habitantes, incluidos los animeros, en el sentido de que la devoción a las benditas almas puede ayudar a organizar el caos emocional que genera el conflicto y que, directa o indirectamente, afecta a todos los porteños.

\section{Referencias}

Aguado, José Carlos (2004). Cuerpo humano e imagen corporal: notas para una antropología de la corporeidad. Ciudad de Mexico: UNAM.

Baro, Martin (2015). Los cristianos y la violencia (1968). Teoría y Crítica de la Psicología, 6, $415-456$.

BBC Mundo (1 de octubre de 2017). El impactante culto a los muertos que existe en Puerto Berrío, Antioquia. WRadio. Recuperado de https://www.wradio.com.co/noticias/sociedad/ el-impactante-culto-a-los-muertos-que-existe-en-puerto-berrio-antioquia/20170110/ nota/3351856.aspx

Bellerose, Martin (2009). Les chrétiens et la sortie de la religion. Bogotá: Antropos.

Blair, Elsa (2005). La violencia frente a los nuevos lugares y/o los otros de la cultura. Nueva antropología, $X X(65), 13-28$.

Borja Gómez, Jaime Humberto (2010). El purgatorio y la mistica en el Nuevo Reino de Granada. En Entre cielos e infiernos: memoria del V Encuentro Internacional sobre Barroco (pp.155-166). Pamplona: GRISO/Universidad de Navarra.

Castillejo, Alejandro (2016). Guerra, cotidianidad y los órdenes globales: notas antropologicas para una relectura de la violencia en Colombia. En Antropologías en Colombia: tendencias $y$ debates (pp. 125-160), editado por Jairo Tocancipá. Popayán: Universidad del Cauca.

Cifuentes, Maria Teresa; Figueroa, Helwar (2004). Corrientes del cristianismo frente a la guerra y la paz en el siglo XX. En Historia del cristianismo en Colombia. Corrientesy diversidad (pp. 373-420), editado por Ana María Bidegain. Bogotá: Taurus. 
Cosoy, Natalio (10 de enero de 2017). Colombia: el impactante culto a los muertos que existe en Puerto Berrío. BBC. Recuperado de https://www.bbc.com/mundo/noticias-america-latina-37987957

Eliade, Mircea (2016). Lo sagrado y lo profano. Barcelona: Paidós.

En Puerto Berrío (Antioquia), cada muerto sin identificar tiene su padrino (21 de octubre 2006). El Tiempo. Recuperado de https://www.eltiempo.com/archivo/documento/CMS-3295035

García, Daniel (2015). Historia y memoria en el Cementerio Central de Bogotá. Karpa, 8, 1-27.

Gauchet, Marcel (2004). Un Monde Désenchanté? Paris: Éditions Ouvrières.

Geertz, Clifford (2009). La interpretación de las culturas. Barcelona: Gedisa.

Girard, Rene (1983). La violencia y lo sagrado. Barcelona: Anagrama.

Halbwachs, Maurice (2004). Los marcos sociales de la memoria. Barcelona: Antropos.

Hervieu-Léger, Daniele (2005). La religión, hilo de la memoria. Barcelona: Herder.

Hoyos, Juan José (30 de noviembre de 2014). Una tutela por las benditas ánimas del purgatorio. El Colombiano.

Londoño, Patricia (2004). Religión, cultura y sociedad en Colombia. Medellíny Antioquia, 18591930. Bogotá: FCE.

López Rodríguez, Mercedes (2005). Las primeras experiencias cristianas en el Nuevo Reino de Granada: Iglesia indiana y cristianismo indigena. En Historia del Cristianismo en Colombia. Corrientes y diversidad (pp. 23-42), editado por Ana María Bidegain. Bogotá: Taurus.

Marzal, Manuel (1997). Investigación e hipotesis sobre religiosidad popular. En Cosmos, hombre y sacralidad (Cap XIX), editado por Marco Rueda; Segundo Moreno. Quito: Abya-Yala.

Nieto, Patricia (2012). Los escogidos. Medellín: Sílaba.

Ortega Martínez, Francisco (ed.), (2011). Trauma, cultura e historia: reflexiones interdisciplinarias para el nuevo milenio. Bogotá: Universidad Nacional de Colombia.

Peláez, Gloria Inés (2001). Un encuentro con las ánimas: Santos y héroes impugnadores de normas. Revista Colombiana de Antropología, 37, 24-41.

Pérez, Daniel Esteban (2014). El Dios de la no-violencia y su propuesta de paz. Pensamiento Humanista, 11, 111-126.

Plata, William Elvis; Figueroa, Helwar (2017). Iglesia, resistencia pacífica y no violencia. La Diócesis de Barrancabermeja, Colombia (1988-2005). Anuario de Historia Regionaly de las Fronteras, 22(1), 137-168. 
Por siete ríos corrió la sangre derramada (23 de abril de 2007). El Tiempo. Recuperado de https:// www.eltiempo.com/archivo/documento/CMS-3525030

Poveda, Rafael (dir.), (22 de abril de 2012). El animero. Testigo directo. Recuperado de https:// www.youtube.com/watch?v=2hN8j-3IlPU

Ricoeur, Paul (2004). La memoria, la historia, el olvido. Buenos Aires: FCE.

Rieff, David (2017). Elogio del olvido: las paradojas de la memoria histórica. Barcelona: Debate.

Rodríguez Camacho, Julián David (2015). Puerto Berrío: entre un cementerio de agua y una creciente de lágrimas. Dimensiones sociales, políticas y culturales de las prácticas funerarias en el conflicto armado (Tesis de maestría). Universidad Nacional de Colombia, Bogotá, Colombia.

Rubiano, Elkin (2017). “Réquiem NN” de Juan Manuel Echevarría: entre lo evidente, lo sugestivo y lo reprimido. Cuadernos de Música, Artes Visuales y Artes Escénicas, XX, 33-45.

Santos Gómez, David (16 de junio de 2013). La creciente de lágrimas del Magdalena. El Colombiano.

Serna Botero, Sonia; Londoño Castaño, Silvia; Aguirre Castro, Cristian (2008). Devoción a las benditas ánimas del purgatorio en Copacabana (Antioquia) (Informe de investigación). Universidad de Antioquia, Medellín, Colombia.

Sorge, Bartolome (1978). La violencia. Madrid: Mateus Cromo.

Jerryson, Michael; Juergensmeyer, Mark; Kitts, Margo (eds.), (2013). The Oxford Handbook of Religion and Violence. Oxford: Oxford University Press.

Thomas, Louis-Vincent (1983). Antropología de la muerte. México: FCE.

Thomas, Louis-Vincent (1991). La muerte: Una lectura cultural. Barcelona: Paidós.

Thomas, Louis-Vincent (1992). La muerte una lectura cultural. Barcelona: Paidós.

Todorov, Tzvetan (2013). Los abusos de la memoria. Madrid: Paidós.

Turner, Víctor (1980). La selva de los símbolos. Madrid: Siglo XXI.

Uribe, María Victoria (2008). Mata que Dios perdona. Gestos de humanización en medio de la inhumanidad. En Veena Das: Sujetos de dolor, agentes de dignidad (pp. 177-192), editado por Francisco Ortega. Bogotá: Universidad Nacional de Colombia/Pontificia Universidad Javeriana.

Walzer, Michael (1983). Guerras justas e injustas. Un razonamiento moral con ejemplos históricos. Barcelona: Paidós. 